\title{
Thyroidectomies from patients with history of therapeutic radiation during childhood and adolescence have a unique mutational profile
}

\author{
Adel Assaad ${ }^{1}$, Laura Voeghtly ${ }^{2}$ and Jennifer L Hunt ${ }^{3}$ \\ ${ }^{1}$ Department of Pathology, Virginia Mason Medical Center, Seattle, WA, USA; ${ }^{2}$ Department of Pathology, \\ University of Pittsburgh, Pittsburgh, PA, USA and ${ }^{3}$ Department of Anatomic Pathology, Cleveland Clinic, \\ Cleveland, OH, USA
}

\begin{abstract}
Radiation in childhood is a known risk factor for thyroid carcinoma, but may also be related to benign nodular hyperplasias. Recent evidence from comparative genomic hybridization indicates that radiation can induce clonal DNA damage in cultured rat thyrocytes. We used a loss of heterozygosity analysis for the loci identified by comparative genomic hybridization to study human thyroids. Thyroids from patients with a history of radiation, patients who had recent therapeutic external beam radiation for laryngeal carcinoma, and patients who had no radiation and underwent incidental thyroidectomy with laryngectomy for laryngeal carcinoma were included. PCR was performed for 18 different genetic loci defined by prior reported comparative genomic hybridization study. A semiquantitative capillary electrophoresis analysis was used and frequency of allelic loss was calculated from the number of losses/the number of informative loci. A total of $\mathbf{4 0}$ cases of thyroids from patients with childhood radiation, 12 cases of recently radiated thyroids, and 15 cases of nonradiated thyroids were included. In the nonradiated and recently radiated thyroids, the mean frequency of allelic loss was $2.3 \%$. In the thyroids from patients radiated as children, the mean frequency of allelic loss was $39 \%$. Losses were seen at every locus with a range of $7-100 \%$ of the cases analyzed (mean $49.6 \%$ ). Radiation in childhood was associated with both benign nodular disease and carcinomas of the thyroid. The frequency of allelic loss was very high in all lesions in these patients, as compared to control thyroid glands. These data from human thyroids support prior cell culture experiments and show that radiation induces genetic mutational damage even in benign proliferative processes in these thyroids.
\end{abstract}

Modern Pathology (2008) 21, 1176-1182; doi:10.1038/modpathol.2008.122; published online 27 June 2008

Keywords: thyroid carcinoma; radiation; BRAF mutation; tumor suppressor gene

Ionizing radiation is a known risk factor for thyroid carcinoma and this was first documented in the 1950s. Exposure to radiation has been studied in two basic scenarios: nuclear fallout (from warfare and nuclear accidents) and the effects of therapeutic radiation. ${ }^{1}$ Many studies have demonstrated an increased risk of thyroid carcinoma in both of these postradiation settings. ${ }^{2-8}$ Although most of the research has been done in the former situation, the latter group is by far the largest; this group includes people who received radiation for malignancies (ie Hodgkin's lymphoma) and for benign conditions (ie thymus enlargement, acne, and tinea). The greatest risk for the

Correspondence: Dr J Hunt, MD, Department of Anatomic Pathology, L25, Cleveland Clinic, 9500 Euclid Avenue, Cleveland, OH 44195, USA.

E-mail: huntj2@ccf.org

This work was presented as a poster presentation at the United States and Canadian Academy of Pathology Annual meeting in March 2006 in Atlanta, Georgia.

Received 10 March 2008; revised and accepted 28 April 2008; published online 27 June 2008 thyroid gland is when radiation occurs in childhood. There can be a long lag time between exposure and side effects; therefore people who were irradiated as children in the 1950s and 1960s have been treated for thyroid diseases over the past two decades.

Molecular genetic alterations have been identified in both papillary carcinoma and in follicular derived carcinomas in both sporadic and radiation-induced clinical scenarios. The best-studied mutations in papillary carcinomas have included ras gene mutations, RET/PTC translocations, and BRAF mutations.

Radiation-induced tumors have been implicated as having higher mutational rates for ras gene mutations and RET/PTC translocations. ${ }^{9-12} \mathrm{~A}$ very well studied group of tumors is from patients in the areas surrounding Chernobyl, where the nuclear disaster in 1986 was responsible for a very high rate of papillary carcinomas. ${ }^{13}$ In those patients, $R E T / P T C$ translocations are very common, particularly the RET/PTC3 type. ${ }^{14}$ Interestingly, BRAF mutations are uncommon in tumors that are thought to be radiation induced. ${ }^{15}$ 
Therapeutic radiation has also been associated with an increased rate of papillary carcinomas. However, the molecular changes in this population are much less well studied. In an in vitro model of radiation-induced thyroid carcinogenesis, Finn et $a l^{16}$ used array comparative genomic hybridization (CGH) to study copy number changes in the genome of cultured irradiated rat thyrocytes. They documented a variety of gains and losses across the genome in fairly consistent and specific sites. Similar studies have also been performed on patient material obtained from patients exposed to Chernobyl nuclear fallout. ${ }^{17,18}$ One group also recently examined a set of tumors from patients who had therapeutic radiation as children and found a low frequency of $B R A F$ mutations. ${ }^{19}$

In this study, we assessed tumor tissue and nontumor thyroid tissue from a large series of patients who had had therapeutic radiation as children, for a variety of clinical reasons. The molecular panel included mutational assessment for $B R A F, K R A S$, and a series of tumor suppressor gene loci. To select the tumor suppressor gene loci, we utilized the reported array CGH data to include the loci with high deletion frequency. ${ }^{16}$

\section{Materials and methods}

The files of the Division of Anatomic Pathology, University of Pittsburgh Presbyterian Hospital were searched for thyroid resection specimens where a clinical history of childhood radiation was documented. Thyroids with any type of pathology were included. Thyroids that were included in laryngectomy resections for treatment of laryngeal squamous carcinomas were used as controls. The control thyroids were divided into two groups: one group had been treated with laryngectomy alone and no preoperative radiation and the other group had received recent preoperative radiation with intent to cure and subsequent salvage surgery.

The hematoxylin-eosin (H\&E) stained slides of the thyroids were reviewed, and the original diagnoses were confirmed. Pathology data were obtained from the original report and from review of the slides. Clinical follow-up was obtained from the patient's electronic medical record by an honest broker. The study was approved by the University of Pittsburgh Institutional Review Board.

One or two paraffin blocks were selected from each case to represent all of the relevant pathologies. Additional slides were cut from these blocks to include one H\&E, six unstained deparaffinized slides, and one final H\&E. In all cases, the block with the most abnormal thyroid tissue was selected as well as one block with normal tissue (normal thyroid or normal lymph node). The first H\&E stained slide was examined and abnormal and normal targets were selected and marked for microdissection. Tissue was then microdissected from the unstained slides under direct visualization using a stereoscopic microscope and a beveled surgical blade. DNA was extracted from the tissue fragments using a standard proteinase $\mathrm{K}$ digestion spin column extraction, using the DNEasy kit with a protocol for paraffin embedded tissue (Qiagen DNEasy, Valencia, CA, USA).

\section{Loss of Heterozygosity Analysis}

Primers designed to yield polymerase chain reaction (PCR) products smaller than 250 base pairs and which were optimized for paraffin-embedded tissue DNA were selected to colocalize with the regions of interest in the genome. The markers and the corresponding loci, along with primer sequences, are given in Table 1 . The primers amplify short tandem repeat units with high polymorphism rates $(>60-80 \%)$ that colocalize with regions containing known or putative tumor suppressor genes. Polymerase chain reactions were performed for tumor and normal tissue under the same conditions using a standard PCR protocol.

The PCR products were analyzed by capillary electrophoresis (Prism 3100; Applied Biosystems Inc., Foster City, CA, USA and Genescan software). The PCR products from the normal tissue were analyzed first to determine whether the patient's DNA was informative at each specific marker locus. The software generates a different peak for each differently sized PCR product when the patient sample is informative at that genetic locus (ie heterozygous for the short tandem repeat unit). The height of the peak represents the fluorescence of the PCR products, which is an indicator of the relative amount of PCR product in the reaction mixture. The ratio of the two different peaks (allele ratio) in normal tissue is approximately $1: 1$, as the two chromosomal copies of the locus should be equally represented in normal diploid cells. The same analysis of the PCR amplifications was performed in the lesion. When the allele ratio in tumor varies from that of the normal by greater than $30 \%$, allelic imbalance is present, and this is designated as loss of heterozygosity (LOH). The fractional allelic loss was calculated as the number of loci with $\mathrm{LOH}$ divided by the total number of loci that were informative of any given patient sample. A statistical analysis was performed using $\chi^{2}$-analysis and the Student's $t$-test (SPSS software, version 11.0, Chicago, IL, USA). A correlation was designated as statistically significant at $P<0.05$.

\section{Sequencing}

DNA was extracted using spin column separation (Qiagen DNEasy). Primer pairs were designed to flank the areas of interest for the mutation points in $B R A F$ (forward: TCATAATGCTTGCTCTGATAGGA and reverse: GGCCAAAAATTTAATCAGTGGA) and KRAS (forward: GGTGAGTTTGTATTAAAAGGTA 
Table 1 Markers and loci used in this study are presented, along with the primer sequence that was utilized

\begin{tabular}{|c|c|c|c|c|}
\hline Primer & Marker & Locus & Forward primer & Reverse primer \\
\hline 1 & D1S226 & $1 \mathrm{p} 22.1$ & CTAGTCAGGCATGAGCG & GGTCACTTGACATTCGTGG \\
\hline 2 & D1S162 & $1 \mathrm{p} 34.2$ & GGGGGAAGAAGTCCGAGTAG & ATAAGGGGAACAGGTCTGGG \\
\hline 3 & D1S199 & $1 \mathrm{p} 34.2$ & GGTGACAGAGTGAGACCCTG & CAAAGACCATGTGCTCCGTA \\
\hline 4 & D3S2403 & $3 p 25.3$ & ACAGATTGAGACCATGTGTCA & CACACTCAAAATACATGAAGGC \\
\hline 5 & D3S3714 & $3 \mathrm{p} 25.3$ & AAGTATGGCAAGGAGTAAGC & GATGTGAGCCACTGCG \\
\hline 6 & D3S1539 & $3 \mathrm{p} 26.3$ & ТСТTТССАТТАСТСТСТССАТАGС & TGAAGCTGTTTAAAACTATTTCTCCA \\
\hline 7 & D5S1993 & 5P13.2 & TCAGTGGAACTCAGGAGG & AGACGGTAAACTTCTGGAGG \\
\hline 8 & D5S2854 & $5 \mathrm{P} 13.3$ & CTTTTGGGAAACAGAAGCAA & CTACAGATGGTACAGTGTAGGACG \\
\hline 9 & D5S1986 & $5 p 13.3$ & AGCTATTCACCTAGTAGAGATTTCT & ACCTAACTGTATTGTCTATGAGAGG \\
\hline 10 & D9S251 & $9 \mathrm{p} 21.3$ & ACTGGAAAGTGCCAAGAGGA & AAGGCTTTGTAGGGGAAAAA \\
\hline 11 & D9S1679 & $9 \mathrm{p} 22.2$ & CACCTCTGCСTGCСAA & TGCTGTGGACCTAACAAAAA \\
\hline 12 & D9S1748 & 9p22.2 & CACCTCAGAAGTCAG AGT & GTGCTTGAAATACACCTTTCC \\
\hline 13 & D10S591 & $10 p 15.3$ & ACCTCGAAGGTCTGTTCTCC & GGCTTTATGGATCATATTAATCCAC \\
\hline 14 & D10S1729 & 10p15.3 & AAGGACTGCATTGTTTTTG & TCAGACACTCTTAGGATTACCC \\
\hline 15 & D11S988 & $11 \mathrm{p} 15.5$ & CAGAAAATAGTTCAGACCACCA & GGGACAAGAGAAAGTTGAACA \\
\hline 16 & D11S4124 & $11 \mathrm{p} 15.5$ & GAACACAATCCCATTTATATTAGC & TCAGCCTCACAAAGTGC \\
\hline 17 & D11S1344 & $11 \mathrm{p} 11.2$ & AGCCTTGTGCTGAACTGTGT & CACAGCGCCTGGCTTGTA \\
\hline 18 & D11S1385 & $11 \mathrm{p} 11.2$ & CCGAGGCTATTGCTGTTTTA & AACCTACTGTGCTGCCAGTC \\
\hline 19 & D13S161 & $13 q 14.3$ & CACACTGCACACAATTCTAAA & CTTAAATTAACGTATTTGGGGTTTT \\
\hline 20 & D13S176 & $13 q 14$ & CTGTGGGATTCCTTAGTGATAC & ATATTCAGACAAAAGCCAAGTTA \\
\hline 21 & D13S153 & $13 q 14.3$ & AGCATTGTTTCATGTTGGTG & CAGCAGTGAAGGTCTAAGCC \\
\hline 22 & D16S392 & $16 q 24.3$ & GATCTTCGGAATACTACTCGT & CCATTGCACTCAGCCTGGGTGAC \\
\hline 23 & D16S422 & $16 \mathrm{q} 24.3$ & CAGTGTAACCTGGGGGC & СTTTCGATTAGTTTAGCAGAATGAG \\
\hline 24 & D16S3057 & $16 q 21$ & CCTGTGTGTATAACTATGTCAAAAT & GCCСTTGAAACTAGGCAATA \\
\hline 25 & D16S3134 & $16 \mathrm{p} 13.3$ & CTGGGAAATTCTGGGA & GGCCAAGGTGTTTGTT \\
\hline 26 & D16S3082 & $16 \mathrm{p} 13.3$ & CCTGCGGAAATAACGGTGA & GTTTCGAGGACAGCCCTGG \\
\hline 27 & D19S561 & $19 q 11$ & CAGCTACTCAAGGGGCTGAG & ACCСCCAGACTTCACTTCCT \\
\hline 28 & D19S400 & $19 q 13.2$ & TCAGCAGCATGAAAATGGAC & GAACCTTCCAGGAGCAACAA \\
\hline 29 & D19S559 & $19 q 13.2$ & GAGGCTGCAGTGAGTCTTGA & CGATTTGGGACATAATAGGTTTG \\
\hline
\end{tabular}

CTGG and reverse: TCCTGCACCAGTAATATGCA). Amplifications were carried out for 35 cycles with annealing temperatures optimized for each primer pair. PCR products were purified using Qiagen MinElute protocol using $20 \mu \mathrm{l}$ of distilled $\mathrm{H}_{2} \mathrm{O}$ applied to the center of spin column membrane immediately following spin down. Cycle sequencing was performed according to the manufacturer's instructions using the BigDye Terminator kit (Applied Biosystems Inc.). Forward and reverse sequences were amplified separately under the same conditions using the same primers as used in the PCR reaction. $0.3 \mu \mathrm{l}$ of DNA was added to $14.7 \mu \mathrm{l}$ of distilled $\mathrm{H}_{2} \mathrm{O}$ and $4 \mu \mathrm{l}$ of diluted Big Dye mix. Sequencing cycles were completed for 25 cycles under optimized primer specific parameters.

Centri-Sep 96 spin columns (Princeton Separations Inc., Adelphia, NJ, USA) were used to transfer amplified DNA into collection tubes for electrophoresis. Samples were denatured at $95^{\circ} \mathrm{C}$ for $5 \mathrm{~min}$ and placed on ice for $2 \mathrm{~min}$; $15 \mu \mathrm{l}$ of Hi-Di formamide (Applied Biosystems) was added to each tube. Sequences were obtained by capillary electrophoreses (ABI 3100; Applied Biosystems) and analyzed using their SeqA software.

\section{Results}

A total of 45 thyroid specimens from patients with a remote history of radiation were identified from our files over a period of 22 years (1982-2004). Of these, 15 were excluded after extensive chart review showed radiation to have occurred in the adult period ( $>21$ years old) or to have not included the thyroid gland in the radiation field. A total of 30 childhood-irradiated thyroids were thus included in the final analysis. The histopathologic diagnoses in the thyroid glands included, chronic lymphocytic thyroiditis (3 cases), benign hyperplastic nodules (11 cases), follicular adenoma (7 cases), follicular carcinoma ( 2 cases), and papillary thyroid carcinoma (7 cases). The patients' age ranged from 30 to 73 years (mean 50 years) and there was a female predominance (20 women, 10 men). The mean interval between irradiation and removal of the thyroid was 39 years (range 3-69 years). The clinical and pathologic features of these cases are shown in Table 3.

A total of 27 control thyroids were included from laryngectomy specimens for laryngeal carcinoma. Control group 1 included 15 patients with no history of radiation and control group 2 included 12 patients with recent therapeutic radiation for the laryngeal carcinoma, ( $<2$ years interval between radiation and surgery). All controls had normal or minimally nodular thyroid glands. In both control groups, there was a male predominance $(21$ men, 6 women) and a mean age of 66 years. The clinical and pathologic features of these cases are shown in Table 2. No cancers of the thyroid or thyroid cancer metastases were identified in the control samples. DNA extraction was successful in all cases. 
Table 2 Demographic information for the control cases is shown

\begin{tabular}{lll}
\hline Gender & Age & Diagnosis \\
\hline $\mathrm{M}$ & 84 & Control (rads) \\
$\mathrm{M}$ & 63 & Control (rads) \\
$\mathrm{M}$ & 59 & Control (rads) \\
$\mathrm{F}$ & 78 & Control (rads) \\
$\mathrm{M}$ & 50 & Control (rads) \\
$\mathrm{M}$ & 70 & Control (rads) \\
$\mathrm{M}$ & 60 & Control (rads) \\
$\mathrm{M}$ & 68 & Control (rads) \\
$\mathrm{M}$ & 51 & Control (rads) \\
$\mathrm{M}$ & 62 & Control (rads) \\
$\mathrm{M}$ & 61 & Control (rads) \\
$\mathrm{M}$ & 82 & Control (rads) \\
$\mathrm{F}$ & 61 & Control (non-rad) \\
$\mathrm{M}$ & 67 & Control (non-rad) \\
$\mathrm{M}$ & 75 & Control (non-rad) \\
$\mathrm{M}$ & 66 & Control (non-rad) \\
$\mathrm{M}$ & 76 & Control (non-rad) \\
$\mathrm{F}$ & 61 & Control (non-rad) \\
$\mathrm{M}$ & 60 & Control (non-rad) \\
$\mathrm{M}$ & 82 & Control (non-rad) \\
$\mathrm{M}$ & 79 & Control (non-rad) \\
$\mathrm{M}$ & 68 & Control (non-rad) \\
$\mathrm{M}$ & 69 & Control (non-rad) \\
$\mathrm{M}$ & 60 & Control (non-rad) \\
$\mathrm{M}$ & 64 & Control (non-rad) \\
$\mathrm{F}$ & 54 & \\
$\mathrm{~F}$ & 67 & \\
\hline $\mathrm{M}$ & 59 (non-rad) \\
\hline & & \\
\hline
\end{tabular}

$\mathrm{M}$, male; F, female; rads, recent history of radiation therapy to neck; non-rad, no history of radiation to the neck.

\section{Loss of Heterozygosity Analysis}

Of the 29 different markers that were utilized, for a total of 10 different well-defined chromosomal loci, the average numbers of informative loci per case was not significantly different between the groups: 19.2 (thyroid from patients who had radiation as children), 22.4 (thyroids without radiation), and 20.9 (thyroids from patients with recent radiation).

The thyroids that were from patients with a history of childhood radiation had significant evidence of $\mathrm{LOH}$ across the entire panel utilized. The mean frequency of allelic loss for all of these cases, including histologically benign and malignant thyroids, was $39 \%$. When broken down by diagnosis, the benign nodular thyroid disease (hyperplastic nodules and follicular adenomas) had a mean frequency of allelic loss of $36 \%$, whereas the malignant tumors, including papillary carcinoma and follicular carcinoma, had a mean frequency of allelic loss of $50 \%(P=0.07)$.

Both of the control groups of thyroid had very low rates of LOH. The nonradiated control group had a mean frequency of allelic loss of $2.0 \%$ and the radiated thyroid control group had a mean of $2.3 \%$. The difference in mean frequency of allelic loss, between the groups of childhoodradiated thyroids (39\%) and both controls (combined 2.1\%), was statistically significant $(P<0.0002)$.

\section{Sequencing}

Only one case demonstrated a mutation in the $B R A F$ gene. This was a papillary carcinoma. The remainder of the cases, including the other eight papillary carcinoma targets, were negative for $B R A F$ and KRAS mutations.

\section{Discussion}

The association between exposure to ionizing radiation and increased risk of thyroid cancer, particularly papillary thyroid carcinoma, has been well documented. ${ }^{5}$ Exposure of the growing thyroid during childhood carries the highest risk of carcinoma and exposure in adults is associated with far less risk. $^{8}$ Even in the absence of malignant transformation, radiation can cause disturbances in thyroid function, usually in the form of clinical or compensated hypothyroidism. ${ }^{20}$ Thyroiditis, autoimmune thyroiditis, and hyperplastic changes are commonly seen in the postradiation setting. ${ }^{21}$

Radiation-induced carcinomas have probably been best studied in patient populations that were exposed to large amounts of radioactive material after events such as the atomic bombs or the Chernobyl disaster. ${ }^{1}$ Less dramatic, but much more common, is exposure to therapeutic radiation of the head and neck. The risk of subsequent thyroid neoplasia in this patient population has been long reported in the literature, especially if treatment occurred during childhood and the teenage years. ${ }^{5}$ Although radiation therapy is now reserved for treatment of conditions with defined morbidity or mortality, in the past low dose radiation was used to treat a host of benign childhood conditions, ranging from adenoid, tonsil, and thymic enlargement to acne or tinea capitis. Because of a long lag time between therapeutic radiation and development of thyroid pathology, which can range up to 25-30 years, many of these patients are only now being seen in clinical practice. Most impressively, treatment with low-dose radiation has been associated with more deleterious events than high dose, because the low-dose radiation causes DNA damage, but does not kill the cells primarily.

The best-studied and well-characterized molecular event that is associated with radiation-induced thyroid neoplasia is the RET/PTC translocations in papillary thyroid carcinoma, which occurs in $25-40 \%$ of cases. ${ }^{14,22,23}$ Ionizing radiation is thought to effect double-stranded DNA breaks that lead to various types of translocations and recombination events. These translocations have also been described in sporadic papillary thyroid carcinoma. The RET/PTC1 translocation (between the RET proto-oncogene and the $\mathrm{H} 4$ gene) caused by a paracentric inversion involving 10q21, is the most frequently described in the sporadic setting and occurs with varying frequencies in radiationinduced papillary thyroid carcinoma. ${ }^{24}$ RET-PTC3 
Table 3 Clinical information and pathologic features for cases and controls included in this study are listed

\begin{tabular}{|c|c|c|c|c|c|}
\hline Gender & Age (diagnosis) & Age (radiation) & $\begin{array}{l}\text { Interval (radiation } \\
\text { to resection) }\end{array}$ & $\begin{array}{l}\text { Reason for } \\
\text { radiation }\end{array}$ & $\begin{array}{l}\text { Histological } \\
\text { diagnosis }\end{array}$ \\
\hline $\mathrm{F}$ & 69 & Child & 64 & Acne & NG \\
\hline $\mathrm{F}$ & 70 & Child & 65 & Lymphoma & NG \\
\hline $\mathrm{F}$ & 56 & 26 & 30 & Hodgkins & PTC \\
\hline $\mathrm{F}$ & 32 & 29 & 3 & Hodgkins & PTC \\
\hline $\mathrm{F}$ & 52 & 13 & 39 & Acne & FA \\
\hline $\mathrm{F}$ & 58 & 7 & 51 & Tonsils and adenoid & NG \\
\hline $\mathrm{F}$ & 50 & 1 & 49 & Thymus & NG \\
\hline $\mathrm{M}$ & 47 & 1 & 46 & Thymus & PTC \\
\hline $\mathrm{F}$ & 58 & Child & 53 & Thymus & NG \\
\hline M & 52 & Adolescent & 38 & Acne & NG \\
\hline $\mathrm{F}$ & 42 & 19 & 23 & Acne & FCC \\
\hline $\mathrm{F}$ & 30 & Child & 25 & Thymus & Graves \\
\hline M & 34 & Child & 29 & Hodgkins & FA \\
\hline M & 55 & 20 & 35 & $\begin{array}{l}\text { Traumatic } \\
\text { brain injury }\end{array}$ & FA \\
\hline $\mathrm{M}$ & 52 & 1 & 51 & Unknown & NG \\
\hline M & 39 & Adolescent & 10 & Acne & PTC \\
\hline $\mathrm{F}$ & 73 & 4 & 69 & Unknown & $\begin{array}{l}\text { PTC and FA } \\
\text { (second site) }\end{array}$ \\
\hline $\mathrm{F}$ & 43 & Child & 38 & Thymus & FA \\
\hline $\mathrm{F}$ & 47 & Child & 42 & Thymus & PTC \\
\hline $\mathrm{F}$ & 44 & 2 & 42 & Thymus & NG \\
\hline $\mathrm{M}$ & 48 & Child & 43 & Unknown & PTC \\
\hline $\mathrm{F}$ & 39 & 15 & 24 & Hodgkins & NG \\
\hline $\mathrm{F}$ & 60 & 16 & 44 & Acne & CLT \\
\hline M & 37 & 17 & 20 & Hodgkins & $\begin{array}{l}\text { FCC and NG } \\
\text { (second site) }\end{array}$ \\
\hline $\mathrm{F}$ & 45 & 11 & 44 & Osteosarcoma & FA \\
\hline $\mathrm{F}$ & 54 & 10 & 44 & Acne & $\begin{array}{l}\text { FA and NG } \\
\text { (second site) }\end{array}$ \\
\hline $\mathrm{M}$ & 53 & 18 & 35 & Unknown & CLT \\
\hline $\mathrm{F}$ & 39 & 1 & 38 & Hemangioma & CLT \\
\hline $\mathrm{F}$ & 67 & 20 & 47 & Alopecia & CLT \\
\hline $\mathrm{M}$ & 68 & Adolescent & 53 & Acne & NG \\
\hline
\end{tabular}

M, male; F, female; NG, nodular goiter; PTC, papillary thyroid carcinoma; FA, follicular adenoma; FCC, follicular carcinoma; CLT, chronic lymphocytic thyroiditis.

The interval from radiation to diagnosis was calculated when an exact age was known and was estimated when it was not known (radiation as a child assume age of 5 years; radiation as an adolescent assume age of 15 years).

(fusion of ret with ELE1) is associated with the radiation-induced papillary thyroid carcinomas that have a short latency period and an aggressive clinical course. ${ }^{25}$ The translocation has been associated with thyroid tumors in the settings of both therapeutic radiation and with radiation from nuclear fallout. ${ }^{10,26,27}$ Although experimental studies have shown that the translocation correlates with the nuclear cytologic features of papillary thyroid carcinoma, translocation alone is unlikely to be sufficient to induce carcinoma. ${ }^{28}$ As with other carcinomas, there are likely to be many different genetic and molecular events involved in the pathway to malignant transformation.

The most common molecular events in general in neoplasia are tumor suppressor gene mutations, which have been described in nearly all types of human tumors. Papillary thyroid carcinomas have a relative low rate of tumor suppressor gene mutations, as measured by LOH to detect allele deletion. ${ }^{29}$ Follicular derived carcinomas, in contrast, have a much higher rate of tumor suppressor gene loss. ${ }^{30}$ Follicular adenomas have low rates, and hyperplastic and non-neoplastic thyroid tissues have negligible rates of tumor suppressor gene loss. ${ }^{30,31}$ The tumor suppressor gene genotype has not been well studied in radiation-induced tumors, either in large-scale studies of the nuclear disasters or in the setting of post-therapeutic radiation.

A recent study has utilized an interesting approach to understand the underlying genetic changes of radiation. ${ }^{16}$ In that report, the authors described using array CGH in cultured $\gamma$-irradiated human thyrocytes to examine the molecular events that occurred in the postradiation setting. The study describes extensive copy number changes at multiple loci at specific spots in the genome. Overall, there were both deletions and amplifications identified. ${ }^{16}$

To investigate the relevance of these in vitro findings to in vivo radiation-induced thyroid neoplasia, we studied the occurrence of LOH in a cohort of patients who had known childhood exposure to ionizing radiation and presented with a nodular thyroid gland. The polymorphic markers used were chosen for their proximity to the areas of chromo- 
somal losses identified in the CGH study by Finn et al. ${ }^{16}$ As control groups we included thyroids from patients who underwent incidental thyroidectomies as part of treatment for laryngeal squamous cell carcinoma that either did or did not have recent (adulthood) radiation therapy to the neck.

Our hypothesis was that irradiation of the thyroid in childhood would cause molecular damage to the thyroid gland follicular cells with possible irreversible chromosomal alterations similar to those seen after radiation of cultured thyrocytes. Because the thyroid is growing and developing during childhood, some of these genomic abnormalities would be expected to be propagated clonally as the thyroid continues to mature. In the controls, the short interval after irradiation, the high dose of radiation, and the lower sensitivity of the mature thyroid gland to radiation should not lead to clonal expansion of genetic abnormalities and thus LOH should not be prevalent in recently radiated or nonradiated thyroids. This basic theory has some support in the literature regarding clonality in thyroid nodules in nodular goiter. Prior studies have used X-inactivation (HUMARA) analyses to prove that the patch size in thyroid is actually quite large. ${ }^{32,33}$ And, in fact, nodules from nodular goiter can have evidence of monoclonal origin. ${ }^{34}$ Thus, we do know that single cells can be progenitors for fairly large nodular areas within the thyroid. One extension of this would be that even cells with radiation-induced DNA damage from low dose radiation can expand clonally in nodules, carrying along the initial DNA damage.

The patients who had a history of radiation as children had variable histologic changes, with both benign and malignant histopathologic diagnoses. Although the dose of radiation was not available due to the long time interval between radiation and surgery (mean 39.8 years), only $37 \%$ had been treated for malignancy (7/19 with known reasons). Overall, the mean frequency of allelic loss of these cases was $39 \%$. The control group thyroids exhibited normal or nodular benign histology. These cases also had extremely low frequency of allelic loss. The difference in frequency of allelic loss between the childhood radiation cohort (39\%) and the control groups $(2.1 \%)$ was statistically significant $(P<0.0002)$. The cases in the study group that had carcinoma had higher frequency of allelic loss than benign lesions ( 36 vs $50 \%, P=0.07$ ), though this did not quite meet statistical significance. These data support the theory that mutations secondary to radiation were propagated through clonal expansion in these phenotypically abnormal thyroids.

We compared the loci showing LOH in our cases to those found by Finn et $a l^{16}$ after radiation to cultured thyrocytes. There was excellent concordance between the cytogenetic loci showing loss by CGH and the finding of LOH using microsatellite markers at 1p, 3p, 5p, 9p, 10p, 11p, 13q, 16q, 16p, and 19q. This suggests that the CGH array data from gamma irradiated cultured human thyrocytes may have highlighted loci in the genome that were at risk for mutagenesis. These hotspots are potentially involved in the pathogenesis of radiation-induced thyroid disease. Another recent study looked at CGH in post-Chernobyl thyroid tumors and found losses at several loci including 9p, 13q, and 16p, which overlap with those seen in our study. ${ }^{18}$

It has also been reported that radiation-induced tumors have a lower frequency of $B R A F$ mutations, ${ }^{19}$ as compared to sporadic papillary carcinomas. ${ }^{15}$ In our study, only $1 / 7$ papillary thyroid carcinomas $(14 \%)$ had a BRAF mutation, which supports the data derived primarily from Chernobyl papillary thyroid carcinoma cases. The benign thyroid pathologies also did not exhibit BRAF or KRAS mutations.

Our data support the theory that molecular damage is induced in the thyrocytes from external radiation, particularly when the radiation occurs in childhood. This molecular damage is not limited to malignancies that develop in these patients, but is also seen in benign nodular disease.

\section{References}

1 Williams ED. Chernobyl and thyroid cancer. J Surg Oncol 2006;94:670-677.

2 Bogdanova TI, Zurnadzhy LY, Greenebaum E, et al. A cohort study of thyroid cancer and other thyroid diseases after the Chornobyl accident: pathology analysis of thyroid cancer cases in Ukraine detected during the first screening (1998-2000). Cancer 2006; 107:2559-2566.

3 Pretorius HT, Katikineni M, Kinsella TJ, et al. Thyroid nodules after high-dose external radiotherapy. Fine-needle aspiration cytology in diagnosis and management. JAMA 1982;247:3217-3220.

4 Imaizumi $\mathrm{M}$, Usa $\mathrm{T}$, Tominaga $\mathrm{T}$, et al. Radiation dose-response relationships for thyroid nodules and autoimmune thyroid diseases in Hiroshima and Nagasaki atomic bomb survivors 55-58 years after radiation exposure. JAMA 2006;295:1011-1022.

5 Sadetzki S, Chetrit A, Lubina A, et al. Risk of thyroid cancer after childhood exposure to ionizing radiation for tinea capitis. J Clin Endocrinol Metab 2006;91: 4798-4804.

6 Schneider AB, Sarne DH. Long-term risks for thyroid cancer and other neoplasms after exposure to radiation. Nat Clin Pract Endocrinol Metab 2005;1:82-91.

7 Likhtarov I, Kovgan L, Vavilov S, et al. Post-Chernobyl thyroid cancers in Ukraine. Report 2: risk analysis. Radiat Res 2006;166:375-386.

8 Kleinerman RA. Cancer risks following diagnostic and therapeutic radiation exposure in children. Pediatr Radiol 2006;36(Suppl 14):121-125.

9 Nikiforov YE, Nikiforova MN, Gnepp DR, et al. Prevalence of mutations of ras and p53 in benign and malignant thyroid tumors from children exposed to radiation after the Chernobyl nuclear accident. Oncogene 1996;13:687-693.

10 Fugazzola L, Pierotti MA, Vigano E, et al. Molecular and biochemical analysis of RET/PTC4, a novel oncogenic rearrangement between RET and ELE1 
genes, in a post-Chernobyl papillary thyroid cancer. Oncogene 1996;13:1093-1097.

11 Wright PA, Williams ED, Lemoine NR, et al. Radiation-associated and 'spontaneous' human thyroid carcinomas show a different pattern of ras oncogene mutation. Oncogene 1991;6:471-473.

12 Bounacer A, Wicker R, Caillou B, et al. High prevalence of activating ret proto-oncogene rearrangements, in thyroid tumors from patients who had received external radiation. Oncogene 1997;15: 1263-1273.

13 Nikiforov Y, Gnepp DR. Pediatric thyroid cancer after the Chernobyl disaster. Pathomorphologic study of 84 cases (1991-1992) from the Republic of Belarus. Cancer 1994;74:748-766.

14 Nikiforov YE. Radiation-induced thyroid cancer: what we have learned from Chernobyl. Endocr Pathol 2006;17:307-317.

15 Takahashi K, Eguchi H, Arihiro K, et al. The presence of BRAF point mutation in adult papillary thyroid carcinomas from atomic bomb survivors correlates with radiation dose. Mol Carcinog 2007; 46:242-248.

16 Finn SP, Smyth P, O’Regan E, et al. Array comparative genomic hybridisation analysis of gamma-irradiated human thyrocytes. Virchows Arch 2004;445:396-404.

17 Detours V, Delys L, Libert F, et al. Genome-wide gene expression profiling suggests distinct radiation susceptibilities in sporadic and post-Chernobyl papillary thyroid cancers. Br J Cancer 2007;97:818-825.

18 Richter H, Braselmann H, Hieber L, et al. Chromosomal imbalances in post-Chernobyl thyroid tumors. Thyroid 2004;14:1061-1064.

19 Collins BJ, Schneider AB, Prinz RA, et al. Low frequency of BRAF mutations in adult patients with papillary thyroid cancers following childhood radiation exposure. Thyroid 2006;16:61-66.

20 Ott RA, Calandra DB, McCall A, et al. The incidence of thyroid carcinoma in patients with Hashimoto's thyroiditis and solitary cold nodules. Surgery 1985;98:1202-1206.

21 Palmer JA, Mustard RA, Simpson WJ. Irradiation as an etiologic factor in tumours of the thyroid, parathyroid and salivary glands. Can J Surg 1980;23:39-42.

22 Sadetzki S, Calderon-Margalit R, Modan B, et al. Ret/PTC activation in benign and malignant thyroid tumors arising in a population exposed to low-dose external-beam irradiation in childhood. J Clin Endocrinol Metab 2004;89:2281-2289.
23 Klugbauer S, Pfeiffer P, Gassenhuber $\mathrm{H}$, et al. RET rearrangements in radiation-induced papillary thyroid carcinomas: high prevalence of topoisomerase I sites at breakpoints and microhomology-mediated end joining in ELE1 and RET chimeric genes. Genomics 2001; 73:149-160.

24 Elisei R, Romei C, Vorontsova T, et al. RET/PTC rearrangements in thyroid nodules: studies in irradiated and not irradiated, malignant and benign thyroid lesions in children and adults. J Clin Endocrinol Metab 2001;86:3211-3216.

25 Nikiforov YE, Rowland JM, Bove KE, et al. Distinct pattern of ret oncogene rearrangements in morphological variants of radiation-induced and sporadic thyroid papillary carcinomas in children. Cancer Res 1997;57:1690-1694.

26 Collins BJ, Chiappetta G, Schneider AB, et al. RET expression in papillary thyroid cancer from patients irradiated in childhood for benign conditions. J Clin Endocrinol Metab 2002;87:3941-3946.

27 Bounacer A, Wicker $\mathrm{R}$, Schlumberger $\mathrm{M}$, et al. Oncogenic rearrangements of the ret proto-oncogene in thyroid tumors induced after exposure to ionizing radiation. Biochimie 1997;79:619-623.

28 Fischer AH, Bond JA, Taysavang P, et al. Papillary thyroid carcinoma oncogene (RET/PTC) alters the nuclear envelope and chromatin structure. Am J Pathol 1998;153:1443-1450.

29 Hunt JL, Fowler M, Lomago D, et al. Tumor suppressor gene allelic loss profiles of the variants of papillary thyroid carcinoma. Diagn Mol Pathol 2004;13:41-46.

30 Hunt JL, Yim JH, Carty SE. Fractional allelic loss of tumor suppressor genes identifies malignancy and predicts clinical outcome in follicular thyroid tumors. Thyroid 2006;16:643-649.

31 Hunt JL, Livolsi VA, Baloch ZW, et al. A novel microdissection and genotyping of follicular-derived thyroid tumors to predict aggressiveness. Human Pathol 2003;34:375-380.

32 Harrer P, Brocker M, Zint A, et al. The clonality of nodules in recurrent goiters at second surgery. Langenbecks Arch Surg 1998;383:453-455.

33 Apel RL, Ezzat S, Bapat BV, et al. Clonality of thyroid nodules in sporadic goiter. Diagn Mol Pathol 1995;4:113-121.

34 Kopp P, Kimura ET, Aeschimann S, et al. Polyclonal and monoclonal thyroid nodules coexist within human multinodular goiters. J Clin Endocrinol Metab 1994;79:134-139. 